\title{
Fatigue in HIV infection was perceived as a barometer of disease progression
}

\author{
Rose L, Pugh LC, Lears K, et al. The fatigue experience: persons with HIV infection. J Adv Nurs 1998 Aug;28:295-304.
}

\section{Question}

How is HIV related fatigue experienced and managed on a daily basis by people with HIV infection or AIDS?

\section{Design}

A hermeneutic phenomenological study.

\section{Setting}

An inner city medical centre in Baltimore, Maryland, USA.

\section{Patients}

5 men and 5 women with HIV infection (mean age 33 y, $80 \%$ African-American) who reported that fatigue had developed since their previous clinic appointment. Fatigue was severe enough to affect activity levels. All participants were receiving disability benefits, lived alone, and 7 reported previous substance abuse.

\section{Methods}

Individual, semistructured interviews of 30-60 minutes were done at the clinic. Topics discussed were personal meanings of fatigue, subjective responses to fatigue, contextual description of when fatigue occurred and the interpretation of the fatigue, the effect fatigue had on daily life, how each person managed the fatigue, and how the fatigue associated with HIV infection was similar or different from non-HIV fatigue. Audiotapes were transcribed, initial interpretations were made, and a team of content experts achieved consensus on the findings. The team consisted of an expert in each of phenomenological research, clinical management of patients with HIV, and fatigue research.

\section{Main findings}

Thematic analysis identified 3 concerns for participants. The first, fatigue as a signal of AIDS, showed that fatigue was seen as a critical factor in the fight against the disabling effects of disease progression and AIDS. Because fatigue was variable, participants continuously evaluated their own fatigue and compared it with that of others. Fatigue was seen as an indication of disease status. "It's a danger sign. A lot of my friends, the ones that went on, that's how it started with them."

The second concern was the body, the mind, the social experience of fatigue. The sensation of the body being tired was intense and was seen as being different from previous experiences with other conditions such as pregnancy and intoxication primarily because the fatigue was felt to be linked to disease progression. Emotional awareness of fatigue was linked to feelings of tearfulness, isolation, and lack of motivation and contributed to a depressed mood and fear of the future. Fatigue led to changes in social aspects such as isolation, frustration on the part of both patients and families, and family members taking on protective roles. "It's like being stuck in a dark, cold, clammy room where you can't get out. You can't go nowhere, you're not really locked in a room, you just can't get enough motivation to get out of it. It's just there."

The third concern was choosing ways to live with fatigue and addiction and involved both personal understandings and actions. Participants chose to push themselves to fight the fatigue, accept the fatigue as inevitable, come to terms with the need to pace themselves, think positively, and improve their lifestyles. Participants felt the need to stop alcohol and drug abuse and to try to come to terms with their disease and its progression while balancing what was important to them in their daily lives. "To sit around and mope about it is a sign of defeat so I find things to do. Then I go and try to take a little nap. You've got to keep your mind on the right perspective. You're not dead.”

\section{Conclusions}

Among people with HIV infection or AIDS, fatigue was seen as a barometer of disease progression. Participants developed ways to deal with the fatigue both physically and emotionally to achieve their desired activities.

Source of funding: no external funding.

For correspondence: Dr Linda Rose, The Johns Hopkins University School of Nursing, 1830 East Monument Street, Baltimore, Maryland 21205, USA. Fax +1 4109557463.

\section{Commentary}

Patients infected with HIV identify fatigue as the symptom that causes the most distress in their lives. ${ }^{1}$ It can be severe enough to interfere with daily activities and employment ${ }^{2}$ and adversely affect quality of life. ${ }^{3}$ The study by Rose $e t$ al offers a clear description of how patients with HIV infection view fatigue.

One must use caution when generalising results from a qualitative study. The study sample comprised men and women from an inner city clinic who were unemployed and receiving disability benefits, all of whom lived with a partner or relative, and some of whom were in recovery programmes for drug addiction. The mean length of time since seroconversion was 3 years. The analysis of the data was comprehensive including the use of 3 experts to review the transcribed interviews and to discuss the analysis until consensus was reached.

How do the findings from this study inform nursing practice? It is important for nurses to recognise that people who are HIV seropositive use the experience of fatigue as a barometer of their illness. As a result, fatigue may be accompanied by fear. Nurses should assess patients for fatigue, provide an opportunity for patients to share their interpretations of their fatigue, be sensitive to their fears, provide support in the decisions they make about managing their illness, and monitor the impact of the decisions on fatigue level. Although a better under- standing of the patient's experience with fatigue helps to equip us better in assisting patients as they struggle to maintain wellbeing in the midst of HIV infection, it is important that interventions be rigorously evaluated to ensure that we do more good than harm.

\section{Adele A Webb, RN, CPNP, PhD Nurse Consultant Perantinides E Nolan Akron, Ohio, USA}

1 Hurley PM, Ungvarski PJ. J Assoc Nurses AIDS Care 1994;5:33-40.

2 Darko DF, McCutchan JA, Kripke DF, et al. Am J Psychiatry 1992;149:514-20.

3 Zander $\mathrm{K}$, Jager $\mathrm{H}$, Palitzsch $\mathrm{M}$, et al. International Conference on AIDS 1993;9:79. 